\title{
A HISTÓRIA, EVOLUÇÃo E CRESCIMENTO DA ELETROQUÍMICA/ELETROANALÍTICA NESTES ÚLTIMOS 25 ANOS
}

Luis Alberto Avaca*

Instituto de Química de São Carlos, Universidade de São Paulo, CP 780, 13560-970 São Carlos - SP

Roberto Tokoro

Instituto de Química, Universidade de São Paulo, CP 26077, 05513-970 São Paulo - SP

\begin{abstract}
THE HISTORY, EVOLUTION AND GROWTH OF ELECTROCHEMISTRY / ELECTROANALYTICAL CHEMISTRY IN THE PAST 25 YEARS. This text describes the development of Electrochemistry and Electroanalytical Chemistry in Brazil from the pioneers at the IQ/USP in the 70's to the present day status. It explains how the members of the scientific community organized themselves before the establishment in 1993 of a specific division within the Brazilian Chemical Society (SBQ) through biennial meetings (Brazilian Symposium of Electrochemistry and Electroanalytical Chemistry - SIBEE). Those SIBEE meetings, in a present number of 12 , are described individually giving some emphasis on their organizers, the invited speakers and the statistics and overall structure of the event. The activities of the Electrochemistry and Electroanalytical Chemistry Division of the SBQ from 1993 are also briefly discussed as well as some considerations are made on the present and future of these fields.
\end{abstract}

Keywords: electrochemistry; electroanalytical chemistry; history.

\section{INTRODUÇÃo}

Este breve relato sobre a Eletroquímica/Eletroanalítica no Brasil precisa começar com um esclarecimento às novas gerações de eletroquímicos e eletroanalíticos sobre a conjunção dos termos utilizada no título. Anos atrás, vários de nós estivemos envolvidos em longas discussões sobre o assunto (algumas até um pouco ásperas), pois alguns defendiam a idéia que a Química Eletroanalítica (ou simplesmente Eletroanalítica) tinha sempre sido considerada como uma parte da Eletroquímica e não uma área per se. Outros, talvez mais sensatos, consideravam que essa separação era parte da tradição que estava se estabelecendo no país em relação a essas áreas. Essa tradição, por sua vez, era uma conseqüência do equilíbrio existente entre os grupos atuantes nesses dois campos. Com o passar dos anos, aqueles militantes no primeiro grupo perceberam que, em muitos casos, a tradição pode ser mais forte que a razão ou a lógica e que esse valor é da maior importância em uma comunidade que quer atingir maturidade e respeito.

Um outro aspecto que merece destaque nesta apresentação é o fato que a Eletroquímica/Eletroanalítica teve um desenvolvimento quase que em paralelo com a própria Sociedade Brasileira de Química (SBQ). Isto será melhor esclarecido ao longo do texto, uma vez que o início desse desenvolvimento deu-se na década de 70 pelo trabalho pioneiro daqueles que podemos chamar de "históricos" sem que, ao mesmo tempo, ficasse estabelecida a divisão correspondente. A Divisão de Eletroquímica e Eletroanalítica (DEQ) só viria a ser criada durante a $13^{\mathrm{a}}$ Reunião Anual da SBQ em maio de 1990, mas sua efetiva implantação nas reuniões anuais só aconteceu em 1993. Nos Apêndices ao final deste texto é mostrado o histórico da participação da Divisão na Reunião Anual da SBQ, assim como os participantes na direção da DEQ desde sua implantação.

\section{A DÉCADA DE 70: OS PRIMEIROS PASSOS}

1966 foi o ano em que várias unidades da Universidade de São Paulo se mudaram para a Cidade Universitária e as disciplinas de Química foram congregadas no Instituto de Química (IQ/USP). Nessa

*e-mail: avaca@iqsc.sc.usp.br época a área de eletroquímica era liderada pelo Prof. Dr. Ivo Jordan, engenheiro químico da Escola Politécnica e a de eletroanalítica pelo Prof. Dr. Eduardo Fausto de Almeida Neves, químico da Faculdade de Filosofia, Ciências e Letras. Este último, formado na Alameda Glete, foi o primeiro a defender doutorado no IQ/USP, sob a orientação do Prof. Dr. Paschoal Américo Ernesto Senise que o considerava seu mais dileto discípulo.

O primeiro mestrado orientado pelo Prof. Jordan foi defendido pelo Sr. Luiz Carlos Guimarães em 1967. Nessa mesma época, o Prof. Dr. Tibor Rabóczkay desenvolvia estudos eletroquímicos em solventes não-aquosos e o Prof. Dr. Hélio Chagas construía o eletrodo de disco-anel. Nesse sentido a implantação da pesquisa em eletroquímica começou com o desenvolvimento de técnicas e a construção de aparelhos.

Em 1973, o Prof. Rabóczkay iniciou os estudos ciclo-voltamétricos de compostos diimínicos, juntamente com o Prof. Dr. Pawel Krumholz e a Profa. Dra. Helena Li Chum. Ainda neste ano, o Prof. Dr. Alejandro Jorge Arvia foi convidado pelo IQ/USP para ministrar um curso de pós graduação em eletroquímica, que veio somar aos trabalhos do Prof. Jordan que regularmente ministrava o referido curso. A influência da escola argentina decorrente deste intercâmbio deu um impulso muito grande às áreas de eletroquímica e eletroanalítica. O Prof. Rabóczkay foi o primeiro a ir ao Instituto Nacional de Investigaciones Fisicoquímicas Teóricas y Aplicadas (INIFTA). Ele foi seguido do Prof. Dr. Roberto Tokoro e vários outros brasileiros que estagiaram no INIFTA, na cidade de La Plata, Argentina.

\section{A INTERIORIZAÇÃO DA ELETROQUÍMICA / ELETROANALÍTICA}

No início da década de 70 foi se estabelecendo no interior de São Paulo a denominada "legião estrangeira". Assim, São Carlos recebeu os Profs. Drs. Ernesto Rafael González e Luis Alberto Avaca na USP, enquanto que o Prof. Dr. Julien Françoise Coleta Boodts concluía seu doutorado e iniciava seus trabalhos na USP de Ribeirão Preto; no final da década, a UFSCar recebia o Prof. Dr. Carlos Ventura D'Alkaine. Esses professores, juntamente com aqueles da USP em São Paulo, formaram um número considerável dos pesquisadores que hoje atuam na área de Eletroquímica/Eletroanalítica. 
Outros destacados formadores de recursos humanos se estabeleceram em diversos pontos do país no final da década de 70 e início da de 80. Entre outros, podemos mencionar a Profa. Dra. Iduvirges Lourdes Müller na UFGRS em Porto Alegre, o Prof. Dr. Carl Hermann Weiss no ITA em São José dos Campos, o Prof. Dr. Marco-Aurelio De Paoli na UNICAMP em Campinas, o Prof. Dr. Oscar Rosa Mattos na UFRJ no Rio de Janeiro, o Prof. Dr. Nelson Ramos Stradiotto na USP, em Ribeirão Preto, o Prof. Dr. Assis Vicente Benedetti na UNESP, em Araraquara, o Prof. Dr. Luis Otávio de Sousa Bulhões na UFSCar, em São Carlos, e os Profs. Drs. Hans Viertler e Ivano Gebhardt Rolf Gutz no IQ/USP. Neste ponto, os autores pedem desculpas se, porventura, algum nome foi esquecido.

\section{VOLTANDO AOS PIONEIROS}

Em 1975, o Prof. Rabóczkay ministrava no IQ/USP curso de pós-graduação sobre aplicação da Eletroquímica ao estudo de compostos químicos e, dentro do curso, introduziu uma inovação fazendo com que os aprendizes realizassem críticas construtivas a teses americanas. Ele também convidava professores palestrantes nacionais, tais como os Profs. Neves, Chagas, González, Avaca, Carl Hermann Weiss (ITA) e Boodts para enriquecer o curso e estabelecer um contato científico entre os eletroquímicos do Estado de São Paulo.

Em 1976 a situação começava a mudar em termos tanto qualitativos como quantitativos. Nos dez anos anteriores houve um considerável desenvolvimento científico estimulado pelos auxílios financeiros de entidades oficiais. A Eletroquímica e a Química Eletroanalítica acompanharam esse processo de desenvolvimento em várias instituições e universidades brasileiras. Em São Paulo aconteciam palestras de conferencistas nas áreas de eletroquímica e eletroanalítica. Os trabalhos científicos dessas áreas eram apresentados nas sessões da SBPC (Sociedade Brasileira para o Progresso da Ciência) dispersos nas áreas de Química Inorgânica, Orgânica, Analítica e Físico-Química mas, em geral, os autores não tinham platéia a não ser as pessoas do próprio grupo.

Nessa mesma época, alguns dos trabalhos produzidos na área eram apresentados nas diversas edições do Encontro Nacional de Corrosão e Eletroquímica organizado pela ABRACO (Associação Brasileira da Corrosão, com sede no Rio de Janeiro) e, a partir de 1978, nas várias edições do Congresso Brasileiro de Energia. Entretanto, esses dois eventos tinham uma platéia muito ampla e os eletroquímicos/eletroanalíticos se sentiam, às vezes, como "peixes fora d'água" no meio de tantos engenheiros (nada contra, mas....!).

Em julho de 1977, foi fundada a SBQ, na reunião anual da SBPC realizada na cidade de São Paulo, na Pontifícia Universidade Católica. Na ocasião foi solicitada a criação da Divisão de Eletroquímica e Eletroanalítica mas a idéia não prosperou naquele momento (talvez pelo fato de ser uma área ainda sem uma massa crítica apropriada). Durante vários anos, os trabalhos da área de Eletroquímica/ Eletroanalítica foram apresentados em sessões de Físico-Química, Química Analítica, etc.

Em função disso, e graças à iniciativa dos "pioneiros" do IQ/ USP, a comunidade Eletroquímica/Eletroanalítica partiu, como veremos a seguir, para a realização de encontros temáticos muito antes de participar ativamente na SBQ. Por isso, a história da DEQ passa necessariamente por esses encontros que melhor definem e caracterizam a evolução e o crescimento dos diversos grupos nessa área.

O momento exigia que ocorresse uma aglutinação dos diferentes grupos de Eletroquímica/Eletroanalítica visando criar condições para um maior intercâmbio no futuro. Este intercâmbio só poderia ter início a partir do conhecimento do que se estava fazendo no país nessa área. Nascia a idéia da realização de um simpósio de
Eletroquímica e Química Eletroanalítica. O Prof. Dr. Gilberto Orivaldo Chierice, que na ocasião havia terminado o seu mestrado com o Prof. Jordan, no então IPEN, e depois fez seu doutoramento com o Prof. Neves, aproximou este último do Prof. Rabóczkay, quem lhe propôs a realização do I Simpósio Brasileiro de Eletroquímica e Eletroanalítica (SIBEE). Esta iniciativa teve apoio irrestrito de toda a comunidade eletroquímica e eletroanalítica, contou com a colaboração financeira inestimável do Prof. Dr. Luciano do Amaral, presidente da Associação Brasileira de Química (ABQ)-Regional de São Paulo e com o patrocínio do Prof. Senise, diretor do IQ/USP, da empresa Micronal, bem como do apoio do Prof. Arvia, diretor do INIFTA, Argentina.

\section{A BREVE E INTERESSANTE HISTÓRIA DO SIBEE}

O I SIBEE ocorreu com enorme sucesso, nas dependências do IQ/USP, nos dias 12 a 14 de outubro de 1978 logo depois de reunião da ABRACO no Rio de Janeiro para facilitar a participação dos cientistas argentinos em ambos os eventos. Os Profs. Neves e Rabóczkay constituíram a comissão organizadora do mesmo. Na época não havia seleção de trabalhos, sendo exigida somente a apresentação de dados originais e um máximo de 6 páginas, assim como discussão oral dos trabalhos em público, garantindo o alto nível científico. Foram apresentados 28 trabalhos de 50 autores, sendo 13 deles estrangeiros ( 9 argentinos). Os trabalhos foram publicados nos anais contendo capa, folha de rosto, comissão organizadora, prefácio e índice dos trabalhos. Os trabalhos, abstracts em inglês e índice de autores totalizaram 166 páginas. Os anais, no formato $21 \mathrm{~cm}$ x 31 $\mathrm{cm}$, foram impressos por um mutirão de pós-graduandos e professores nas dependências do Instituto de Ciências Biológicas da USP, em São Paulo, numa época em que o mimeógrafo a óleo era ainda rodado manualmente.

É interessante notar que dos 37 participantes nacionais no I SIBEE, 13 deles (que aparecem em mais de 50\% dos trabalhos em 1978) também estiveram no XII SIBEE em 2001 onde contribuíram com $25 \%$ do total de cerca de 300 trabalhos apresentados nesse último evento. Vida longa aos velhos mestres e aos jovens (na época) seguidores! ${ }^{1}$

O II SIBEE foi realizado mais uma vez nas dependências do IQ/ USP de 9 a 11 de junho de 1980, mantendo o espírito do I Simpósio em que os resumos seriam apresentados na forma estendida. A comissão organizadora ficou constituída pelos Profs. Neves, Rabóczkay, Tokoro e Paulo Teng-An Sumodjo. Apesar dos problemas gerais do país terem aumentado nos dois anos anteriores, com a Universidade vivendo um período inédito de crise, tudo em conseqüência da situação mundial de crescente tensão, a divulgação e o intercâmbio ocorreram com êxito. Um desafio mundial no campo de uso e armazenamento de energia despertou interesse nas pesquisas de baterias e a comunidade eletroquímica brasileira prontamente atendeu ao apelo internacional com proeminente participação. Foram apresentados 31 trabalhos com participação de 51 autores (EUA 1, Reino Unido 1 e Argentina 1). O bem-sucedido II Simpósio teve o apoio mais uma vez do Prof. Amaral, presidente da ABQ-Regional São Paulo e do Prof. Senise, diretor do IQ/USP, alem do Dr. Carlos Eduardo de Paes Barreto, presidente do Conselho Regional de QuímicaIV Região e do Prof. Dr. Shigueo Watanabe, diretor executivo da Academia de Ciências do Estado de São Paulo. Os anais seguiram os moldes do I Simpósio, contendo 284 páginas.

O III SIBEE ocorreu nas dependências do SENAC, na cidade de São Carlos - SP, de 4 a 7 de abril de 1982. A comissão organizadora foi constituída pelos Profs. D’Alkaine, Bulhões e Rocha Fo (UFSCar), González, Chierice e Avaca (IFQSC/USP). Várias inovações foram introduzidas, como a excelente orientação para a apresentação de 
trabalhos em painéis, e a sua filosofia, assim como a vinda de diversos conferencistas convidados estrangeiros: Prof. Dr. Roger Parsons, presidente da Sociedade Internacional de Eletroquímica (ISE); Dr. K. Kordesch, secretário da ISE; Prof. Dr. Derek Pletcher, Universidade de Southampton (Reino Unido); Prof. Dr. B. Tremillon, Universidade de Paris (França); Prof. Dr. W. Ronald Fawcett, Universidade de Guelph (Canadá); Prof. Dr. George G. Guibault, Universidade de New Orleans (EUA). Foram apresentados 80 trabalhos com quase 140 autores (Chile 21, Argentina 15, França 2, EUA 1). Os patrocinadores foram: CNPq/Pronaq, SPI, SDC, Finep, Fapesp, Fund. UFSCar, IFQSC/USP, SBQ, ABQ, Acesp e as empresas Zanini S/A e Salgema S/A. Os anais ${ }^{2}$ foram publicados em dois volumes, contendo 741 páginas, no formato $21 \mathrm{~cm} \mathrm{x} 31 \mathrm{~cm}$.

O IV SIBEE ocorreu mais uma vez na cidade de São Carlos SP, de 15 a 18 de abril de 1984. A comissão organizadora foi constituída pelos Profs. Adhemar C. Rúvolo Fo, Bulhões e Rocha $\mathrm{F}^{\circ}$ (UFSCar), González e Chierice (IFQSC/USP), Franco Decker (Unicamp) e Eng. José Antonio Nunes de Carvalho (Acesita, MG). Os conferencistas convidados para as plenárias foram: Profs. Drs. H. Gerisher (Alemanha), Sergio Trasatti (Itália), Fred C. Anson (EUA). Foram apresentados 106 trabalhos, com participação de 193 autores (Chile 13, Argentina 35, Portugal 1, Índia 5, Reino Unido 2, EUA 1, Finlândia 1), publicados em anais de 610 páginas, formato $15 \mathrm{~cm} \mathrm{x}$ $21 \mathrm{~cm}$, encadernação fraca e letra miúda (tamanho 10); os abstracts em inglês foram abolidos no final dos Anais e incluídos no começo de cada trabalho. Patrocinadores: CNPq, Fapesp, Finep, DQ/UFSCar, IFQSC/USP, IF/Unicamp, SENAC e as empresas Banco Itaú e Lápis Johan Faber.

Em 1986, o evento retornou à cidade de São Paulo. A comissão organizadora do V SIBEE foi constituída pelos Profs. Neves, Rabóczkay, Viertler, Sumodjo, Maria Encarnación Vasquez Suárez e Graciliano de Oliveira Neto (IQ/USP) e Rocha Fo (UFSCar). Dois professores estrangeiros foram convidados para as conferências plenárias: George G. Guibault (EUA) e Jenõ Havas (Hungria). Foram apresentados 150 trabalhos, com a participação de 236 autores (Chile 16, Argentina 40, Uruguai 3, EUA 1, Canadá 1, Portugal 1, Índia 6, Japão 4). Os trabalhos completos (6 páginas) foram publicados em anais de 945 páginas, formato $21 \mathrm{~cm} \mathrm{x} 31 \mathrm{~cm}$; os abstracts em inglês voltaram a aparecer no final do livro e faltou numeração nos trabalhos. Patrocinaram: IQ/USP, Fapesp, Coordenadoria de Atividades Culturais da Universidade de São Paulo - Codac/USP, Codage, CRQ 4-Região, SBQ, ABQ - regional SP e as empresas Instrutécnica e Metrimpex.

O VI SIBEE ocorreu de 28 a 30 de março de 1988, em São Paulo, no IQ/USP, sendo a comissão organizadora composta pelos Profs. Raboczkay, Viertler, Gutz, Sumodjo, Oliveira Neto, Nina Coichev, Silvia Helena Pires Serrano e Biaggio F. Giannetti (IQ/ USP), e Rocha Fo (UFSCar). Os patrocinadores que colaboraram com o evento foram: IQ/USP, Codac/USP, Fapesp, SBQ, ABQ, CRQ - 4- Região e as empresas CG Instrumentos Científicos Ltda., Digimed Indústria Eletrônica Ltda. e Hellma Sul América. Os 86 trabalhos foram impressos em livro de anais contendo 737 páginas, com capa amarela de brochura. As conferências plenárias tiveram participação dos professores: E. Yeager, B.D. Cahan, D. Scherson e H. Hanson (EUA), e James H.P. Utley (Reino Unido). No encerramento, os seguintes tópicos foram abordados: homenagem ao Prof. Senise, aprovação do relatório anterior, decisão de que a data do SIBEE permanecesse na semana santa, tiragem dos trabalhos feita pela Comissão, recomendação de todos os participantes para a apresentação de painéis, título, endereço, resumo, palavras-chaves, classificar o trabalho pelos autores conforme orientação circular a semelhança da SBPC e do Encontro Latino Americano de Química, e deixar uma hora livre para que todos os expositores pudessem participar e interagir; foi mantida a total autonomia da comissão organizadora local. Para o próximo evento foi escolhida Ribeirão Preto, sendo coordenador o Prof. Boodts e, em seguida, outro local indicado foi Campinas, sendo que o Prof. Decker já deveria participar como adjunto da comissão organizador do próximo evento.

O VII SIBEE ocorreu de 8 a 11 de abril de 1990, no Stream Palace Hotel, na cidade de Ribeirão Preto - SP. Foi a primeira vez que o SIBEE deixou o eixo São Paulo - São Carlos. A comissão organizadora foi composta pelos Profs. Boodts, Stradiotto, Adalgisa Rodrigues de Andrade, Glaico Chiericato Júnior, José Fernando de Andrade e Josealdo Tonholo (FFCLRP/USP), e Decker (Unicamp). Os patrocinadores do evento foram: CNPq, Fapesp, Finep, Departamento de Química da FFCLRP/USP, Gráfica da Faculdade de Odontologia de Ribeirão Preto da USP, Prefeitura do Campus Administrativo de Ribeirão Preto da USP, CODAC/USP e as empresas Instrutécnica Ltda., Átomo Química Artigos para Laboratórios Ltda. e Refrescos Ipiranga S.A. As conferências plenárias tiveram a participação dos seguintes professores estrangeiros: Sergio Trasatti e Bruno Scrosati (Itália), Claude Lamy (França) e Dieter Britz (Dinamarca). Uma boa iniciativa que foi introduzida neste SIBEE foi a realização de mini-conferências com menor tempo (aproximadamente $30 \mathrm{~min}$ ), para as quais foram convidados conferencistas nacionais: Profs. Edson Antônio Ticianelli, Auro Atsushi Tanaka, M.C.A. Fantini e Percio A.M. Farias. Os 118 trabalhos científicos (Argentina 25, Chile 3, Itália 7, Israel 1, EUA 2, Uruguai 3, França 1 e Peru 1), de 5 a 7 páginas, sofreram uma análise rigorosa e foram publicados em dois volumes de anais. $\mathrm{O}$ volume 1 , com sumário das plenárias, miniconferências e título/autores dos trabalhos e sua paginação até a página 322, acrescida de 22 resumos em inglês e, no final, um índice completo de autores. O volume 2 , iniciando com o sumário dos títulos/autores de trabalhos e sua página remissiva, até página 706, acrescida de 32 resumos em inglês e, no final, um índice completo de autores. A capa é branca, com logotipo do símbolo circular coreano in-shing, em azul e vermelho, saindo dos mesmos o circuito de uma fem. Os anais não foram distribuídos por ocasião do evento, devido ao atraso na liberação de verba do CNPq para a impressão (lembram-se do confisco das poupanças?), tendo sido recebidos somente meses depois do evento. A ata da assembléia de encerramento do VII SIBEE, em 11/4/1990, aprovou a criação da Divisão de Eletroquímica e Eletroanalítica da Sociedade Brasileira de Química. A elaboração de documento a ser enviado à SBQ ficou a cargo de Roberto Tokoro, de maneira que a criação desta divisão deveria ser avaliada na assembléia da $13^{\text {a }}$ Reunião Anual da SBQ, em Caxambu - MG.

O VIII SIBEE ocorreu no Centro de Convenções da Unicamp, em Campinas - SP, de 13 a 15 de abril de 1992. A comissão organizadora foi constituída pelos Profs. De Paoli, Decker, Oliveira Neto, Luiz Manoel Aleixo, Oswaldo Espírito Santo Godinho, Annete Gorenstein, Maristella Decker, Maurício U. Kleinke e Célia R. Freire, todos da Unicamp. Os patrocinadores que colaboraram neste SIBEE foram: Fapesp, Pró-Reitoria de Extensão e Assuntos Comunitários da Unicamp, Banespa, Setor de Publicações do Instituto de Física "Gleb Wataghin" da Unicamp, Faculdade de Engenharia da Unicamp e a empresa Instrutécnica Ltda. Os 122 trabalhos foram publicados em livro de anais de 762 páginas, com capa de brochura com belíssima figura de eletrodeposição de zinco, forma de dentritos em branco, em fundo negro. Os trabalhos foram divididos em sessões de $\mathrm{A}$ até $\mathrm{H}$ sem explanação sobre a razão desta distribuição. Faltaram os resumos em inglês, um índice remissivo de autores e também um sumário dos trabalhos. A assembléia da $15^{\text {a }}$ Reunião Anual da SBQ, realizada em Caxambu - MG, em 30 maio de 1992, aprovou a criação da Divisão de Eletroquímica e Eletroanalítica, parte das reivindicações que a comunidade eletroquímica e eletroanalítica havia estabelecido na assembléia do VII SIBEE. Em 8 de junho de 1992, foi encami- 
nhado oficio ao presidente da SBQ comunicando a criação da Divisão de Eletroquímica e Eletroanalítica, com a constituição dos cargos de diretor e dois vice-diretores, e sobre a soberania da assembléia do SIBEE nas decisões da comunidade. Por motivo de mudança e viagem, o então presidente do VIII SIBEE, Prof. Decker, não realizou a eleição da diretoria da nova divisão, a qual foi realizada por consulta escrita à comunidade. Após a apuração ficaram eleitos os Profs. Luis Alberto Avaca, como diretor, Assis Vicente Benedetti, como vice-diretor, e Ivano Gebhardt Rolf Gutz, como tesoureiro. O resultado da eleição ficou consignado num oficio encaminhado ao Presidente da Sociedade Brasileira de Química

Em 1994, o IX SIBEE ocorreu juntamente com XI CIBAE (Congresso Ibero-Americano de Eletroquímica), no Hotel Vacance, na cidade de Águas de Lindóia - SP, de 3 a 9 de abril. A comissão executiva foi constituída pelos Profs. D'Alkaine, Sonia Regina Biaggio e Rosa Maria Bonfá (UFSCar), González, Artur de Jesus Motheo e Ticianelli (IFQSC-USP). A comissão cientifica foi formada pelos Profs. Neves, Boodts, Avaca, Bulhões e De Paoli. O apoio, patrocínio e promoção foram de: ParqTec/São Carlos, CNPq, Fapesp, FBBrasil, Finep, Capes, Prefeitura Municipal de São Carlos, Varig, Conectur, UFSCar, USP, SBQ (DEQ) e ISE. A realização do CIBAE juntamente com o SIBEE estimulou o intercâmbio cientifico e tecnológico entre a comunidade iberoamericana. A conferência plenária foi proferida pelo Prof. Arvia, do INIFTA. Também foram ministradas outras 30 conferências convidadas. Os 282 trabalhos foram publicados em livro de resumos, assim distribuídos: I Eletroquímica Fundamental (68); II - Materiais de Eletrodo e Eletrólise (56); III - Eletroanalítica (41); IV - Conversão Eletroquímica de Energia (17); V - Corrosão, Eletrodeposição e Tratamento de Superfície (66); VI - Eletroquímica Molecular (22); VII - Eletroquímica Industrial e Engenharia Eletroquímica (12). O livro em brochura, que contém um índice de autores no final, tem na capa um mapa-mundi expandido, fundo verde, em que os países iberoamericanos aparecem em amarelo e os demais em branco; um circuito elétrico está montado, saindo um borne das Américas e fechando na Península Ibérica, em traço azul e ainda um galvanômetro interposto em série, com o ponteiro acusando transferência de conhecimento. A orelha da contra-capa apresenta um breve histórico do CIBAE, de maneira muito agradável de se ler.

O X SIBEE aconteceu nas dependências da Universidade Federal de São Carlos, em São Carlos - SP, de 27 a 30 de outubro de 1996. A comissão organizadora ficou constituída pela comissão executiva e pela comissão científica. A primeira ficou a cargo dos Profs. Bulhões, Orlando Fatibello Filho, Ernesto Chaves Pereira e Ivani Aparecida Carlos (UFSCar), e Edson Ticianelli, Roberto Manuel Torresi, Germano Tremiliosi Filho e Luíz Henrique Mazo (IQSC/ USP). A segunda, dos Profs. Oliveira Neto, Avaca, González e Susana Inés Córdoba de Torresi. O apoio, patrocínio e promoção ficaram sob a responsabilidade de CNPq, Fapesp, Capes, Departamento de Química da UFSCar, Instituto de Química de São Carlos da USP e das empresas Acumuladores Reifor, Biodina, CESP, Instrutécnica Ltda., Representações Uirapuru e Schott-Zeiss do Brasil Ltda. As conferências plenárias foram proferidas pelos Profs. D.A. Butry, J. Mc Breen e A. Wieckowsky (EUA). Os 177 trabalhos, selecionados pela comissão científica, cada ocupando 3 páginas de papel A4, foram distribuídos nas seguintes seções: EF - Eletroquímica Fundamental (43), EA - Eletroanalítica (29), CE - Corrosão, Eletrodeposição e Tratamento de Superfícies (32), EMO - Eletrodos Modificados com Óxidos ou Complexos Inorgânicos (20), EMP - Eletrodos Modificados com Polímeros Eletroativos (22), EML - Eletrodos Metálicos e Ligas Metálicas (10), BEM - Eletroquímica Molecular e Bioeletroquímica (9), CEE e EIE - Conversão Eletroquímica de Energia e Eletroquímica Industrial e Engenharia
Eletroquímica (12). Os trabalhos foram publicados em livro de resumos com 557 páginas, sendo que as sessões precedidas de folha de rosto, amarela, arrolando todos os trabalhos nas mesmas, e, ao final, aparece um índice remissivo de autores. A capa de brochura, ilustrada, quando totalmente aberta apresenta a "bateria de chumbo/ácido", em homenagem a Gaston Planté (1859), nas cores azul água no fundo e contorno de amarelo ouro patê, letras em azul escuro.

A primeira vez que o SIBEE saiu do Estado de São Paulo foi em 1999. Assim, o XI SIBEE foi realizado no Hotel Salinas de Maragogi (eqüidistante em $120 \mathrm{~km}$ de Recife e Maceió), em Maragogi - AL. A comissão organizadora foi indicada na assembléia de São Carlos, em 1996, cabendo aos grupos de Eletroquímica de Maceió e Recife a sua composição e decisões na organização. A comissão foi constituída pelos Profs. Marília O.F. Goulart, Flamarion Diniz, Josealdo Tonholo, José Carlos Pereira Silva e Marcelo Navarro. Como comissão científica atuaram os Profs. González, Boodts, Bulhões, De Paoli, Fatibello Fo e Avaca. Os conferencistas convidados foram os Profs. Ernesto R. González (IQSC/USP), Christian Amatore (França), Karl Kadish (EUA), Christopher Brett (Portugal), Hector Abruña (EUA), Daniel Scherson (EUA) e Luis A. Avaca (IQSC/USP). As mini-conferências ficaram a cargo dos Profs. Julien Boodts, Ernesto Pereira, Annette Gorenstein, Edson Ticianelli, Luiz Antonio de Faria, Lauro Kubota, Ione F. de Oliveira, Nelson Stradiotto, Jane F. Zoppas e Auro Atsushi Tanaka. Os workshops tiveram a coordenação dos Profs. De Paoli, González e Silvia Maria Leite Agostinho, sendo os participantes de cada especialidade os Profs. Sonia R. Biaggio, Tulio Matencio, Wilson A. Gazotti Júnior, Roberto Torresi, Oscar Rosa Mattos, Marcia Laudelina Arruda Temperini, Teresa Vielstich, Germano Tremiliosi Fo, Edson Ticianelli e Mercedes Vilullas. Os patrocinadores do evento foram: Associação dos Profissionais de Química do Estado de Alagoas, CRQ - $17^{\text {a }}$ Região, CFQ - Conselho Federal de Química, Reitoria da Universidade Federal de Alagoas, Reitoria da Universidade Federal de Pernambuco, SBQ, SIBAE Sociedade Ibero-americana de Eletroquímica, Finep, Fapesp, Fapeal, CNPq e as empresas Triken S.A., Ultrachem Ltda. e Baterias Moura S.A. Os 240 trabalhos foram publicados em livro de resumos. Um relatório sobre o evento foi disponibilizado na Internet, mostrando o amadurecimento do SIBEE, facilitando o acesso a trabalhos, endereços, informações úteis de todo tipo, constituindo um excelente banco de dados que muito contribui para a memória do Simpósio.

O XII SIBEE ocorreu no Hotel Serra Azul, na cidade de Gramado - RS, nos dias 22 a 26 de abril de 2001. A comissão organizadora foi constituída pelos Profs. Iduvirges Lourdes Muller, Denise Shermann Azambuja, Emilse A. Martini, Jane Zoppas Ferreira, Luis Frederico Pinheiros Dick, Reinaldo S. Gonçalves, Adrea M. Bernardes, Carlos Arthur Ferreira, Clarisse Piatnicki e Gelsa E. Englert. A comissão cientifica ficou composta pelos Profs. Azambuja, González, Muller, Gutz, Avaca, Bulhões, De Paoli e Rocha Fo. O levantamento de dados deste evento foi muito fácil de ser feito, pois à semelhança ao ocorrido no evento anterior de Maragogi, todas as informações ficaram disponíveis na Internet. Foi o primeiro SIBEE do novo milênio, correspondendo plenamente à qualidade, brilho e grandeza do evento. O histórico do SIBEE foi resgatado e é de leitura muito agradável. Merece especial registro que foi o primeiro evento a disponibilizar os pouco mais de 300 trabalhos em CD-Rom, economizando papel e facilitando o arquivo nas bibliotecas. Foram cinco conferências plenárias de convidados estrangeiros, a saber: Profs. Erika Kálmán (Hungria), Noburu Oyama (Japão), Alejandro Arvia (Argentina), Mario Ferreira (Portugal) e Salvatore Daniele (Itália). Outras quatro conferências plenárias foram proferidas pelos seguintes convidados nacionais: Oscar Rosa Mattos (UFRJ), Teresa Iwasita (IQSC/USP), Marco-Aurelio De Paoli (Unicamp) e Ivano G. Gutz (IQ/USP). A capa do programa do evento apresenta na folha de rosto 
um fundo do portal de Gramado e logotipo em destaque do XII SIBEE.

\section{ENQUANTO ISSO, NA DEQ/SBQ...}

Como foi mencionado anteriormente, a Divisão de Eletroquímica e Eletroanalítica (DEQ) foi efetivamente implantada na Reunião Anual da SBQ de 1993. Nesse primeiro ano, somente 46 trabalhos foram apresentados, mas esse número cresceu para 70 em 1994 e atingiu um máximo histórico de 147, em 1995 (quando houve um workshop da área com vários convidados do exterior - vide quadro abaixo).

A partir desse momento a situação se estabilizou e, em média, são apresentados cerca de 100 trabalhos por ano. Essa evolução pode ser vista no gráfico mostrado no Apêndice 2, que também inclui os trabalhos apresentados nas doze edições do SIBEE. Nele pode-se observar que o SIBEE, pela sua tradição de vários anos e a especificidade dos assuntos, tem um crescimento regular, enquanto que a DEQ/SBQ precisa de promoção (ou de ausência de SIBEE no ano) para superar a marca de 100 trabalhos na reunião anual.

Nesse sentido, as diversas diretorias da DEQ tem tentado atrair a comunidade eletroquímica/eletroanalítica às reuniões anuais da SBQ, convidando destacados pesquisadores nacionais e internacionais para proferir conferências temáticas, conforme está detalhado no quadro abaixo.
Em vista disso, podemos considerar que a situação atual é satisfatória pois permite que a comunidade eletroquímica/eletroanalítica tenha encontros regulares e altamente proveitosos. Adicionalmente, a apresentação dos trabalhos na forma de painéis muito bem organizados facilita a participação de alunos em estágios iniciais da pesquisa. Por outro lado, a interação com outras áreas da Química fornece ao aluno uma visão mais ampla do campo de trabalho para o futuro. Nesses aspectos, as reuniões anuais da SBQ têm um papel da maior importância na formação de recursos humanos para o desenvolvimento do Brasil.

\section{E O FUTURO?}

O futuro da Eletroquímica/Eletroanalítica é muito promissor. Praticamente todas a sub-áreas destas especialidades estão sendo exploradas pelas centenas de pesquisadores atuantes no momento. Quase todas as regiões do país têm, ao menos, um grupo ativo nessas áreas e a tendência é uma expansão lenta mas constante.

Por outro lado, a comunidade eletroquímica/eletroanalítica tem mostrado uma grande capacidade para projetar internacionalmente as pesquisas que estão sendo localmente executadas. Uma mostra disso é o fato que, após a organização do Congresso da Sociedade Iberoamericana de Eletroquímica em Águas de Lindóia em 1994, já foi organizado no País um Congresso Internacional de Impedância (Angra dos Reis - RJ, 1998) e em 2003 será realizada a Reunião

\begin{tabular}{lll}
\hline RA ano & Conferencista & Instituição \\
\hline $18^{\text {a }} 1995$ & E.J. Calvo & Univ. de Buenos Aires, Argentina
\end{tabular}

Título da conferência

Caracterización de hidrogeles policatiónicos para inmovilización y conexión eléctrica de enzimas a electrodos

\begin{tabular}{lll}
\hline $18^{\text {a }} 1995 \quad$ B. Scharifker & Univ. Simón Bolivar, Venezuela & $\begin{array}{l}\text { La dimensión espacial en los procesos de } \\
\text { electrocristalización }\end{array}$ \\
\hline
\end{tabular}

\begin{tabular}{|c|c|c|c|}
\hline $18^{\mathrm{a}} 1995$ & J. Garcia-Antón & Univ. Politec. Valencia, Espanha & Aplicación de sistemas micelares em electroquímica \\
\hline
\end{tabular}

\begin{tabular}{llll}
\hline $19^{\text {a }} 1996$ & M.-A. De Paoli & Unicamp, Campinas & Efeito fotoeletroquímico em polímeros condutores \\
\hline $19^{\text {a } 1996}$ & J. Rubim & IQ/USP, São Paulo & $\begin{array}{l}\text { Estudo espectroeletroquímico (reflectância no UV-Vis } \\
\text { e SERRS) do azul de metileno em eletrodo de prata. } \\
\end{array}$ \\
& & Caracterização de adsorbatos e produtos de redução \\
\hline
\end{tabular}

\begin{tabular}{lll}
\hline $19^{a} 1996 \quad$ I. Gonçalves de Souza & UFSC, Florianópolis & $\begin{array}{l}\text { Presente e futuro da eletrodissolução anódica em } \\
\text { sistemas de injeção em fluxo }\end{array}$ \\
\hline
\end{tabular}

\begin{tabular}{lll}
\hline $20^{\text {a }} 1997 \quad$ P. Bartlett & Univ. Southampton, Inglaterra & $\begin{array}{l}\text { Enzymes, electrons and electrodes - Developments in } \\
\text { biosensors and bioelectronics }\end{array}$
\end{tabular}

\begin{tabular}{llll}
\hline $22^{\mathrm{a}} 1999$ & E.R. González & IQSC/USP, São Carlos & Eletrocatálise e poluição ambiental \\
\hline $23^{\mathrm{a}} 2000$ & S. Isied & Univ. Nova Jersey, EUA & $\begin{array}{l}\text { Long range electron transfer across proteins and pep- } \\
\text { tides with the polyproline II and collagen structures }\end{array}$ \\
\hline
\end{tabular}

24 $2001 \quad$ E.J. Calvo Univ. de Buenos Aires, Argentina

Assembling biomolecules on electrode surfaces molecular recognition and signal generation

24a $2001 \quad$ A.R. Hillman Univ. Leicester, Inglaterra

Composition and dynamics of electroactive polymer films 
Anual da Sociedade Internacional de Eletroquímica (ISE) em São Pedro - SP.

\section{AGRADECIMENTOS}

Os autores agradecem o extenso e cuidadoso trabalho realizado pelo Prof. R. C. Rocha $\mathrm{F}^{o}$ na revisão e criterização do texto original assim como as diversas sugestões sobre o mesmo.

\section{APÊNDICE 1}

\section{DIVISÃO DE ELETROQUÍMICA E ELETROANALÍTICA}

Número de filiados: 250 (atual)

1990/1992

DIRETOR:

Roberto Tokoro (O Prof. Tokoro foi indicado como diretor "pro-tempore" e ficou encarregado de providenciar a implantação da Divisão e a eleição de sua primeira diretoria)

1992/1994

DIRETOR:

VICE-DIRETOR:

TESOUREIRO:

Luis Alberto Avaca

Vicente Assis Benedetti

Ivano G. Rolf Gutz

1994/1996

DIRETOR:

VICE-DIRETOR:

Luis Alberto Avaca

TESOUREIRO:

1996/1998

DIRETOR:

VICE-DIRETOR:

TESOUREIRO:

1998/2000

DIRETOR:

VICE-DIRETOR:

TESOUREIRO:

2000/2002

DIRETOR:

VICE-DIRETOR:

TESOUREIRO:

Nelson Ramos Stradiotto

Sérgio Antonio Spinola Machado

Pedro de Lima Neto

Auro Atsushi Tanaka

Romeu Cardozo Rocha Filho

Sérgio Antonio Spinola Machado

Luis Alberto Avaca

Romeu Cardozo Rocha Filho

Luis Otávio de Sousa Bulhões

\section{NOTAS}

1. Os nomes, em ordem alfabética de sobrenomes, são: Luis A. Avaca, Assis V. Benedetti, Julien F. C. Boodts, Luis O. S. Bulhões, Ernesto R. González, Ivano G. R. Gutz, Artur J. Motheo, Eduardo F. A. Neves, Tibor Rabóczkay, Romeu C. Rocha Fo, Nelson R. Stradiotto, Edson A. Ticianelli e Roberto Tokoro.

2. Os resumos desses trabalhos, assim como os do IV SIBEE, foram indexados no Chemical Abstracts, o que permitiu ampla divulgação dos eventos no exterior. Isto levou à venda de diversos exemplares dos anais para os EUA.

\section{APÊNDICE 2}

Trabalhos Apresentados no SIBEE e na DEQ/SBQ desde 1978

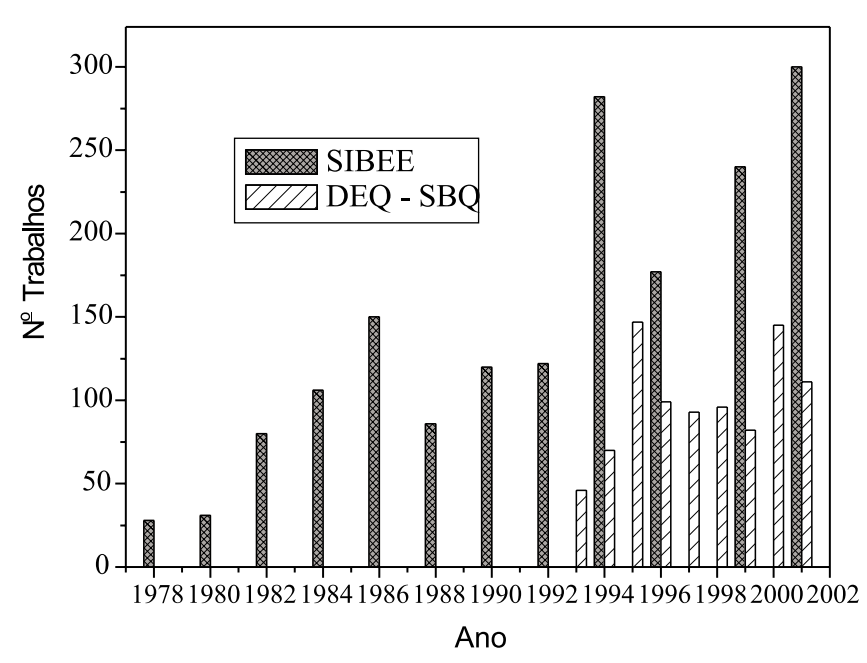

